\title{
Lead Based Metal Organic Frameworks(Pb-MOFs): Anion Influence, Luminescence and Gas Adsorption Study
}

\author{
SHAMAILA IRAM ${ }^{1 *}$, MUHAMMAD IMRAN ${ }^{1}$, FARAH KANWAL ${ }^{1}$, SHOOMAILA LATIF ${ }^{2}$, ZAFAR IQBAL ${ }^{3}$ \\ ${ }^{1}$ Institute of Chemistry Punjab University Lahore-Pakistan \\ ${ }^{2}$ Department of chemistry, Lahore, University of Lahore, 54000, Pakistan
}

\begin{abstract}
Two Lead based organic frameworks ( $1 \& 2$ ) have been synthesized using 4,6-dihydroxy-2mercaptopyrimidine $\left(H_{2} D M P\right)$ as organic linker. Lead nitrate (1) and Lead acetate (2) salts were used to investigate their influence on morphology of resulting MOFs, adsorption capacities and luminescence behaviour. Structure and morphology of these MOFs was established on the basis of UV/Vis, Fourier transform infrared spectroscopy (FTIR), Scanning electron microscopy (SEM), ${ }^{1} H$ NMR, energy dispersive spectroscopy (EDS), thermogravimetric analysis (TGA) and X-ray diffraction technique. Brunauer-Emmett-Teller (BET) studies revealed better $\mathrm{N}_{2}$ adsorption capacity for 1 (surface area $814 \mathrm{~m}^{2} / \mathrm{g}$ ) when compared with 2 (surface area $196 \mathrm{~m}^{2} / \mathrm{g}$ ). Photoluminescence behaviour of $(1 \& 2)$ was investigated in solid state at room temperature and has been attributed to metal-centred $s \rightarrow p$ transition.
\end{abstract}

Keywords: Bidentate ligands, Lead, Luminescence, Metal organic frameworks.

In past decade, hybrid inorganic organic frameworks have attracted much attention due to their appropriate properties and fascinating applications [1-8]. Several organic linkers particularly having carboxylate and hydroxyl moieties [9-14] have been widely employed to assemble frameworks of versatile structural design as well as excellent physical properties. Among metal ions, much attention have been paid on transition and lanthanide metal ions compared to main group elements. Among main group elements, Lead metal ion exhibits flexible coordination environment due to the lone-pair and large ionic radius. Moreover, it possesses large spin orbit coupling constant, an important characteristic for developing luminescent complexes [15]. Some notable examples of Lead based MOFs are $\left[\mathrm{Pb}(\mathrm{HL})(\mathrm{SCN})_{2}, \mathrm{HL}=\right.$ bis pyridyl hydrazone; $\left[\mathrm{Pb}\left(\mu_{2}-\mathrm{Br}\right)(\mathrm{Br})\left(\mathrm{L}_{1}\right)\right]_{,} \mathrm{L}_{1}=2^{\prime}$ neutral hydrazone; $\{[\mathrm{Pb}(\mathrm{HL})$ $\left.\left.(\mathrm{OAC})^{2}\right]-\mathrm{ClO}_{4}\right\}_{n}, \mathrm{HL}=\mathrm{N} 2$-(1-(2-pyridyl) ethylidene)nicotinehydrazideetc] [16-18].

Keeping in view versatile structural chemistry of lead ion and in continuation of our recent work [16], we present in this paper, synthesis of two MOFs originating from 4,6dihydroxy-2-mercaptopyrimidine ( $\left.\mathrm{H}_{2} \mathrm{DMP}\right)$ as organic linke. Comparative studies of anion influence, adsorption as well luminescence are also part of this manuscript.

\section{Experimental part}

Methods and Materials

4,6-dihydroxy-2-mercapto-pyrimidine, were procured from Sigma-Aldrich while lead nitrate and lead acetate trihydrate were purchased from Uni-chem. All chemicals were of reagent grade and used without further purification. Gallenhamp melting point apparatus was used for the melting point determination. The IR spectra were recorded using Cary $630 \mathrm{FTIR}$ Agilent Technologies. ${ }^{\mathrm{H}} \mathrm{H}$ NMR spectra were recorded on Avance AV-400 spectrometers. The morphology of the sample was done by NovaNano 450SEM ûeld emission scanning electron microscope (FESEM) and model vega tescan LMU. Thermogravimetric Analyzer (TGA) was performed from 30 to $800^{\circ} \mathrm{C}$ at a heating rate of $10 \mathrm{C} / \mathrm{min}$ under a nitrogen atmosphere using SDT Q600 instrument. The Powder x-ray diffraction patterns of MOFs ( $1 \& 2$ ) were obtained by diffractometer (Equinox 2000,
Thermo scientific, USA) using CuK $\alpha_{1}$ radiation. Also Brunauer-Emmett-Teller (BET) based ${ }^{1} \mathrm{~N}$ gas adsorption studies were made by using Tri Star II 3020 version 2.00 , a BET surface area measurement instrument.

\section{Synthesis of MOFs}

Synthesis of MOF (1)

A mixture of lead acetate trihydrate $(0.4 \mathrm{~g}, 1 \mathrm{mmol}, 10$ $\mathrm{mL} \mathrm{H}_{2} \mathrm{O}$ ) and 4,6-dihydroxy-2-mercapto-pyrimidin ( $0.2 \mathrm{~g}$, $1 \mathrm{mmol}, 15 \mathrm{~mL} \mathrm{H}_{2} \mathrm{O}$ ) was stirred for $4 \mathrm{~h}$ at ambient temperature in a round bottom flask. The resulting solution was concentrated upto $10 \mathrm{~mL}$. Colorless precipitates formed were filtered off, washed with water $(05 \mathrm{~mL})$ thrice, dried and kept in dessicator at room temperature for further use. Colorless ppt. Yield: $48 \%$. m.p.: $190^{\circ} \mathrm{C}$. IR: C-OH 1197 , $\mathrm{C}=\mathrm{N} 1682 \mathrm{~cm}^{-1}{ }^{1} \mathrm{H}$ NMR $\left(400 \mathrm{MHz}\right.$, DMSO- $\left.d_{6}\right): \delta=4.10(\mathrm{~s}$, $1 \mathrm{H},-\mathrm{SH}), 3.16\left(\mathrm{~s}, 3 \mathrm{H}, \mathrm{CH}_{3}\right)$. Analytical data: Formula of the MOF (1); C 20.24 (19.76); H 2.25 (1.92); Pb 43.64 (42.98)\%; N 5.90 (5.76)\%; S 6.75 (6.44)\%.

\section{Synthesis of MOF (2)}

This MOF was synthesized as described for MOF ( 1 ) by using lead nitrate $\left(0.4 \mathrm{~g}, 1 \mathrm{mmol}, 10 \mathrm{~mL} \mathrm{H}_{2} \mathrm{O}\right)$ and 4,6dihydroxy-2-mercapto-pyrimidine $(0.2 \mathrm{~g}, 1 \mathrm{mmol}, 15 \mathrm{~mL}$ $\mathrm{H}_{2} \mathrm{O}$ ). Colorless ppt. Yield: $58 \%$. m.p.: $230^{\circ} \mathrm{C}$. IR: $\mathrm{C}=\mathrm{N} 1618$ $\mathrm{Cm}^{-1}$. ${ }^{1 H}$ NMR $\left(400 \mathrm{MHz}, \mathrm{DMSO}-d_{6}\right): \delta=4.11-4.15(\mathrm{br}, 1 \mathrm{H}$, -SH). Analytical data: Formula of the MOF(2); C 10.11 (9.80); H 0.85 (0.74); Pb 43.59 (42.80)\%; N 11.75 (11.32)\%; S $6.75(6.01) \%$.

\section{Results and discussions}

Lead based MOFs ( $1 \& 2$ ) were synthesized under hydrothermal conditions by reacting respective lead salts and ( $\left.H_{2} D M P\right)$ in $1: 1$ as outlined in Scheme 1 . Both these MOFs $(\mathbf{1} \& \mathbf{2})$ are air stable solids and insoluble in water and common organic solvents. These are only soluble in DMSO. Their reduced solubility might be attributed to their polymeric/framew ork nature. Moreover, both are colourless and have been obtained in good yield of ( $48 \% 1,58 \% 2$ ) has been obtained.

To establish the coordination mode of 4,6-dihydroxy-2mercaptopyrimidine ( $\mathrm{H}_{2}$ DMP) towards lead ion, FTIR 


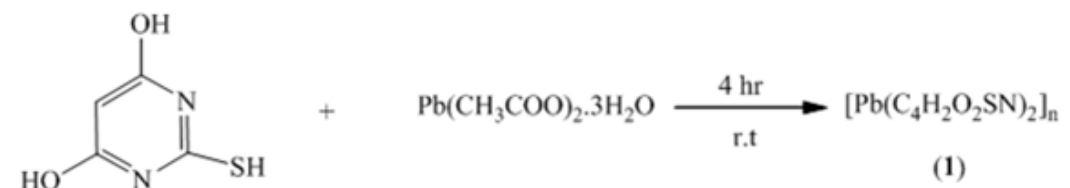<smiles>Oc1cc(O)nc(S)n1</smiles>

$\mathrm{Pb}\left(\mathrm{NO}_{3}\right)_{2}$.

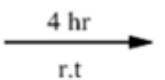

$\left[\mathrm{Pb}\left(\mathrm{C}_{4} \mathrm{H}_{2} \mathrm{O}_{2} \mathrm{SN}\right)_{2}\right]_{n}$

(2)

spectra of this linker and both MOFs have been compared. The IR spectra of Pb MOFs ( $1 \& 2$ ) lacks band for $-\mathrm{OH}$ group thus indicating deprotonation and subsequent involvement with lead ion. Moreover, the stretching frequency for $\mathrm{C}=\mathrm{N}$ moiety in $\mathrm{H}_{2} \mathrm{DMP}$ at $1643 \mathrm{~cm}^{-1}$ has been shifted at 1682 and $1618 \mathrm{~cm}^{-1}$ in MOF 1 and 2 respectively. This comparison revealed that each $\mathrm{H}_{2}$ DMP linker behave in a monoanionic bidentate manner.

${ }^{1} \mathrm{H}$ NMR spectra of both MOFs ( $1 \& 2$ ) were recorded in DMSO- $d_{6}$ and are shown in Figure 1. Chemical shifts values have been given in experimental section. The main feature of these spectra is the absence of signal for - $\mathrm{OH}$ proton in MOFs $(\mathbf{1} \& \mathbf{2})$, thus supporting its deprotonation (16). The relatively broad singlets in the ranges $4.10-4.15 \mathrm{ppm}$ have been attributed to -SH moiety [19].

(1)

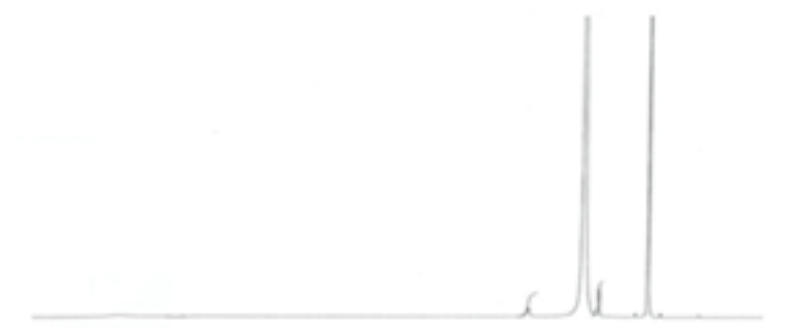

(2)

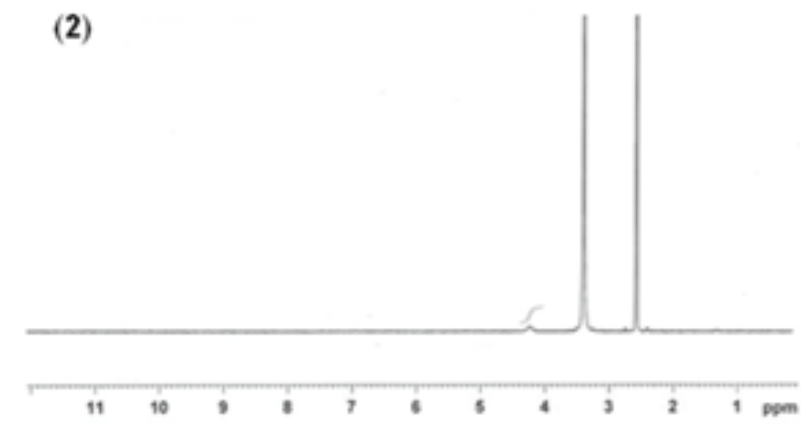

Fig. 1. ${ }^{1 H}$-NMR spectra of MOFs (1 - 2)

\section{Scanning electron microscopy}

The morphology of the resulting MOFs ( $1 \& 2$ ) was studied by SEM and micrographs of both these MOFs are shown in Figure 2-3. The SEM image of MOF (1) showed shiny particles as an irregular aggregation compared to more porous flake shaped crystalline particles MOFs (2). These morphological features of both these MOFs are comparable with related MOFs such as (Pb-MOF; $\left[\mathrm{Pb}\left(\mathrm{C}_{6} \mathrm{H}_{6} \mathrm{O}_{2} \mathrm{~S} \mathrm{~N}_{2}\right), \mathrm{Pb}\left(\mathrm{C}_{14} \mathrm{H}_{8} \mathrm{O}\right)\right.$ ] ] (20), [Cu-BTC (BTC: Benzene tricarboxylate ligand Ni-TOX (TOX: oxalic and trimesic acid] [21-22]. $=4.998 \AA$ ).
Scheme 1. Reaction scheme for the formation of MOFs (1 - 2)

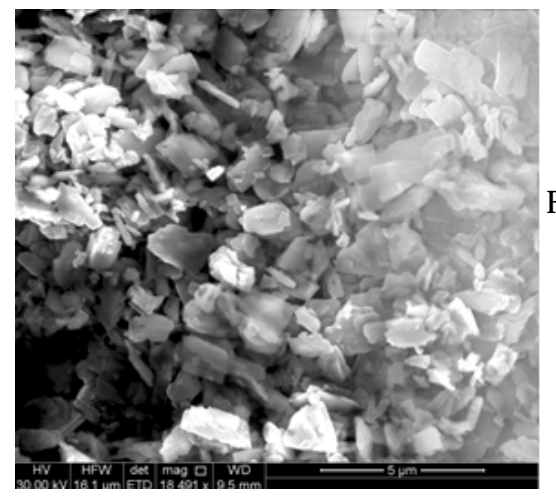

Fig. 2. Scanning electron micrograph (SEM) of MOF (1)

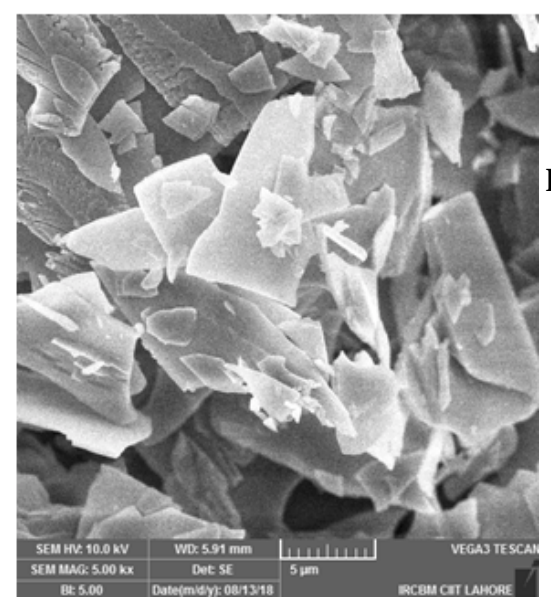

Fig. 3. Scanning electron micrograph (SEM) of metal organic frameworks (2)

\section{Powder X-ray diffraction studies}

$X$-ray powder diffraction study was employed to elucidate the structural information of these MOFs $(\mathbf{1} \& \mathbf{2})$. The respective XRD pattern of $\mathbf{1} \& \mathbf{2}$ are shown in Figures (4-5) respectively. Both these MOFs possess similar crystal form i.e orthorhombic, however differentspace group Pbca and $\mathrm{cmma}$ respectively. However, both exhibit different sharp peaks (MOFs (1) at $2 \theta=12.54^{\circ}, 19.00^{\circ}, 28.00^{\circ}, 29.00^{\circ}$, $31.44^{\circ}$; lattice parameters, $a=6.0268 \AA, b=11.3635 \AA$, $c$ $=19.3485 \AA$, MOF (2), $2 \theta=11.17^{\circ}, 19.00^{\circ}, 22.47^{\circ}, 29.84^{\circ}$, $33.85^{\circ}$; lattice parameters, $a=5.6118 \AA, b=5.6114 \AA$, $c$

The crystallite size estimation $15.97 \mathrm{~nm}$ for 1 and 16.18 $\mathrm{nm}$ for $\mathbf{2}$ was made by Debye-Scherrer formula (23), thus presenting MOF 1 as better candidate for BET studies.

\section{Thermal Stability}

The thermal stability of MOFs $(\mathbf{1} \& \mathbf{2})$ was determined by TGA in a nitrogen atmosphere from room temperature to $800^{\circ}, C$ and TGA curves are presented in Figure 6 . In MOF (1), first weight loss was observed between $30-155^{\circ} \mathrm{C}$ that can be attributed to release of water molecules [24]. Finally, a gradual weight loss approximately $48 \%$ of their initial mass occurred from 200 to $790^{\circ} \mathrm{C}$ thus leaving $\mathrm{PbO}$ as residue. 


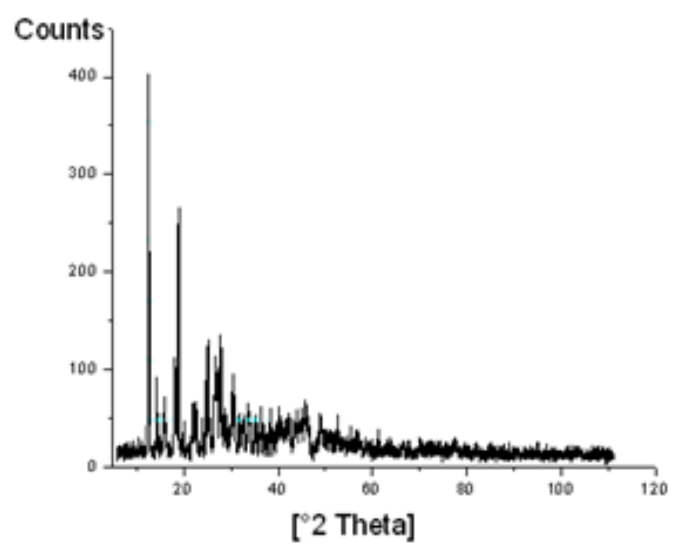

Fig. 4. Powder X-ray diffraction (PXRD) of MOF (1)

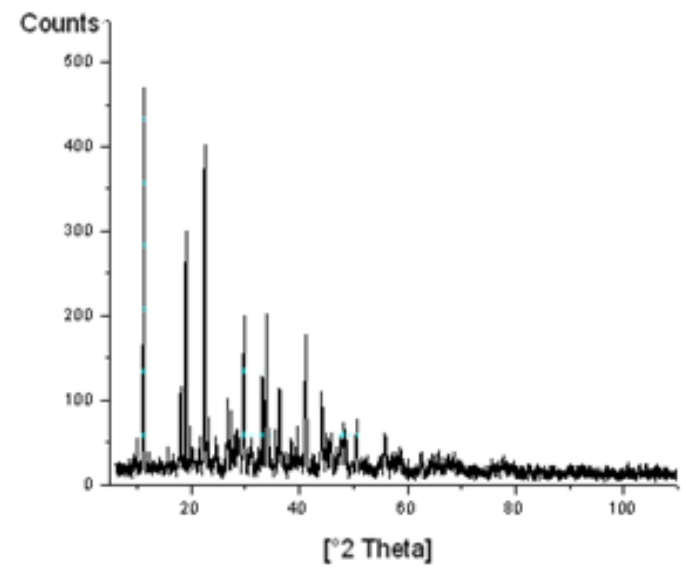

Fig. 5. Powder X-ray diffraction (PXRD) of MOF (2)

Compared to MOF 1, TGA curve of MOF (2) exhibits sharp weight loss in the range from 160 to $780^{\circ} \mathrm{C}$. This reveals that MOF (2) degraded thermally more easily relative to MOF (1).

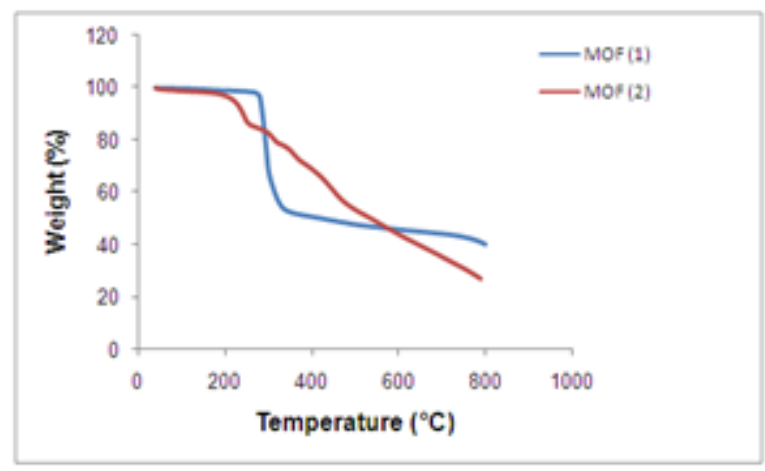

Fig. 6. TGA curves of thermal decomposition of MOFs $(1 \& 2)$

\section{Photoluminescence studies}

The luminescence behaviour of both MOFs ( $1 \& 2$ ) were investigated in solid state at room temperature and their spectra are shown in Figure $7(a \& b)$. Both these MOFs (1 $\& 2$ 2) display a similar emission band at $514 \mathrm{~nm}$ which can be assigned to a metal-centered $s \rightarrow p$ transition as proposed by Vogler (25). Similar emission bands have also been assigned in the literature [ $\mathrm{Pb}$-based MOFs like $\left[\mathrm{Pb}\left(\mathrm{H}_{2} \mathrm{O}\right) \text { (tip) }\right]_{n^{\prime}} \mathrm{Pb}_{3}\left(\mu_{4}-\mathrm{O} \text { (tip) }{ }_{2}\right]_{\mathrm{n}}$ (tip = 5-tert-butylisophthalic acid) [26].
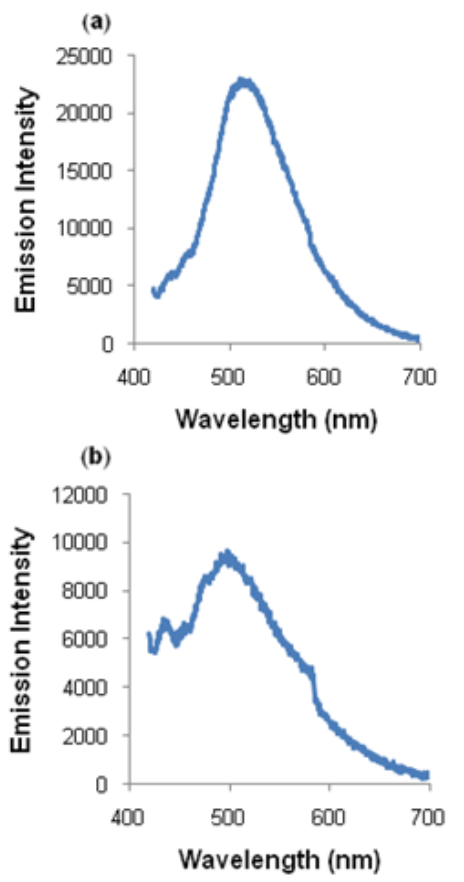

Fig. 7. Emission spectra of MOFs ( $1 \& 2)$

\section{Surface Area and Porosity}

\section{Characterization}

Figures 8-11 displayed $\mathrm{N}_{2}$ adsorption isotherms for $\mathrm{Pb}$ MOFs ( $1 \& 24)$ measured at $77 \mathrm{~K}$. These isotherms are described as Type II isotherm according to the IUPAC classification that corresponds to mono-and multilayer physical adsorption. The estimated BET surface area for MOF (1) is $814 \mathrm{~m}^{2} / \mathrm{g}$ and total pore volume was $0.12 \mathrm{~cm}^{3} /$ g. While it is $196 \mathrm{~m}^{2} / \mathrm{g}$ with total pore volume $0.20 \mathrm{~cm}^{3} / \mathrm{g}$ for MOF (2). Because of more BET surface area, MOF (1) showed significant adsorption capacity for $\mathrm{N}_{2}$ relative to $\operatorname{MOF}(2)$.

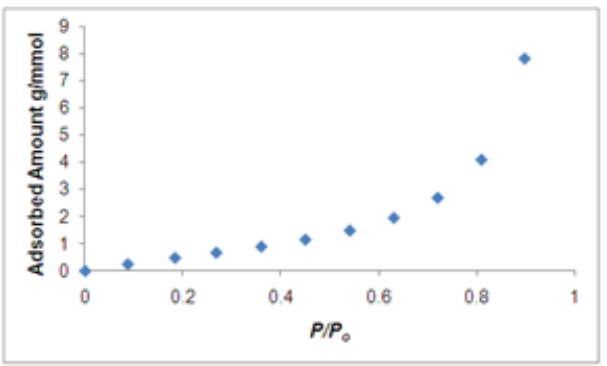

Fig. 8. $\mathrm{N}_{2}$ isotherm of MOF (1)

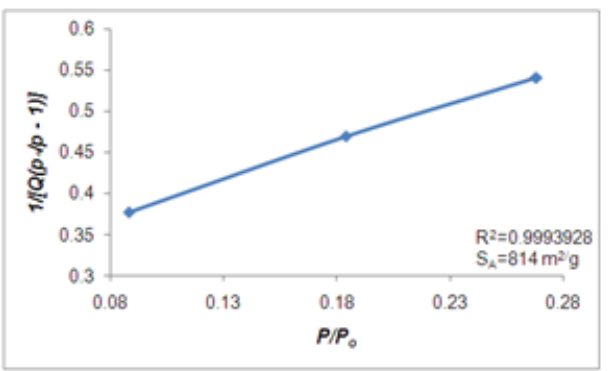

Fig.9. BET analysis of MOF (1)

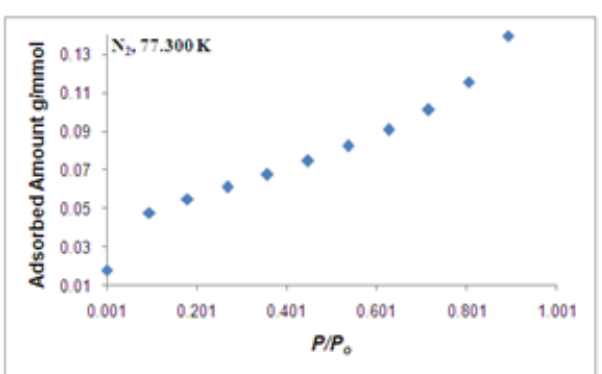

Fig.10. $\mathrm{N}_{2}$ isotherm of MOF (2) 


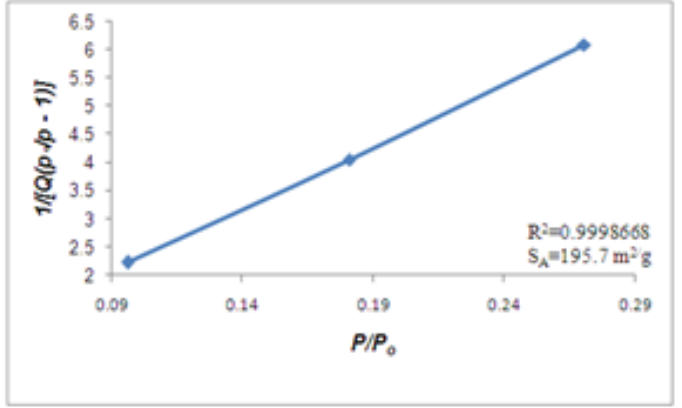

Fig.11. BET analysis of MOF (2)

\section{Conclusions}

In this work, two lead-MOFs have been synthesized and structurally characterized.Both MOFs exhibited similar orthorhombic crystal form with differentspace groups. Both these MOFs display strong emission and could be considered as promising candidate for developing light emitting diode devices. BET studies of MOF 1 reveal it to be a better system for sequestring of gases and other pollutants from environment.

\section{References}

1. S. KITAGAWA, R., KITAURA, S. I., NORO, Angew. Chem., Int. Ed.,43, 2004, p. 2334-2375.

2. C. N. R. RAO, S., NATARAJ AN, R., VAIDHYANATHAN, Angew. Chem., Int. Ed. 43, 2004, p. 1466-1496.

3. D. BRADSHAW, J. B., CLARIDGE, E. J., CUSSEN, T. J., PRIOR, M. J., ROSSEINSKY, Acc. Chem. Resear., 38, 2005, p. 273-282.

4. A. K. CHEETHAM, C. N. R., RAO, R. K., FELLER, Chem. Commun., 46, 2006, 4780-4795.

5. D. MASPOCH, D., RUIZ-MOLINA, J. Chem. Soc. Rev., 36, 2007, 770818.

6. G: FEREY, Chem. Soc. Rev., 37, 2008, p. 191-214.

7.C. N. R. RAO, A. K., CHEETHAM, A., THIRUMURUGAN, J. phys. Condens. Matert., 20, 2008, p. 083202.

8. G: FEREY, Dalton Trans., 23, 2009, p. 4400-4415.

9. B. XIAO, P. J., BYRNE, P. S., WHEATLEY, D. S., WRAGG, X. B., ZHAO, A. J., FLETCHER, K. M. ,THOMAS, L., PETERS, J. S. O., EVANS, J. E., WARREN, W. Z., ZHOU, R. E., MORRIS, Nat. Chem., 1, 2009, p. 289294.
10. P. JAIN, V., RAMACHANDRAN, R. J., CLARK, H. D., ZHOU, B. H., TOBY, N. S., DALAL, H. W., KROTO, A. K., CHEETHAM, J. Am. Chem. Soc., 131, 2009, p. 13625-13627.

11.S. SUN, C. B., MURRAY, D., WELLER, L., FOLKS, A., MOSER, Sci., 287, 2000, p. 1989-92.

12. H. J. LEE, W., CHO, S., JUNG, M., OH, Mater., 21, 2009, p. 674-677. 13. K: KOH, A. G., WONG-FOY, A. J., MATZGER, J. Am. Chem. Soc., 131, 2009, p. 4184.

14.L. SHOU-HU, G., SHAO-KANG, L., SHI-XIONG, G., YUN-NAN, Cryst. Growth Des., 10, 2010, p. 49-503.

15. I, MUHAMMAD, M., ANDREAS, N., BEATE, S., HANS-GEORG, M., UWE, G., PETRA, W. M., NORBERT, Dalton Trans., 44, 2015, p. 924.

16. G. S. MASOUMEH, G., SERVATI, S., VLADIMIR, B., ANTONIO, M., GHODRAT, B., ANTONIO, F., ANTONIO, G., PIOTR, S., VLADIMIR, M. K., ALEXANDER, K., ALAN, R., P., CATALINA, CrystEngComm., 18, 2016, p. 5375-5385.

17. G. MAHMOUDI, V., STILINOVI/E, A., BAUZA, A., FRONTERA, A., BARTYZEL, C., RUIZ-PEREZ, A. M., KIRILLOV, RSC Adv., 6, 2016, p. 60385-60393.

18. M. GHODRAT, V. G., ATASH, R. H., SABINA, C., ROSA, A., MOJTABA, B., ALESSIA, P., M. MARIUSZ, S., FILIP, K., MERCEDES, A. S., DAMIR, Inorg. Chem., 56, 2017, p. 9698-9709.

19. N. J. GOODWIN, W., HENDERSON, B. K., NICHOLSON, J. K., SARFO, J., FAWCETT, D. R. J., RUSSELL, J. Chem. Soc., Dalton Trans., 45, 1997, 4377-4384.

20. I. SHAMAILA, I., MUHAMMAD, K., FARAH, L., SHOOMAILA, I., ZAFAR, S., HANS-GEORG, chem. select.

21. C. CHMELIK, J., KARGER, M., WIEBCKE, J., CARO, J. M., BATEN, Micro. Meso. Mater., 117, 2009, p. 22-32.

22. M. SAIRA, R., UZAIRA, H., NOMAN, Int. J. Innovation and Scientific Research., 15, 2015, p. 443-451.

23. J. M. YANG, Q., LIU, W. Y., SUN, Micro. Meso. Mater., 190, 2014, p. 26-31.

24. S. A. DEODWARE, D. J., SATHE P. B., CHOUDHARI, T. N., LOKHANDE, S. H., GAIKWAD, Arab. J. Chem., 2016.

25.A. VOGLER, A., PAUKNER, H., KUNKELY, Coord. Chem. Review., 97, 1990, p. 285-297.

26. B. QI-BING, P. JUAN-JUAN, W. HONG-YANG, F. CHUN-HUA, Z. ZHENWEI, New. J.Chem., 39, 2015, p. 431.

Manuscript received: 4.10 .2018 